F O U N D T I O N O F C O M P U T N G A N D D E C I S I O N C I E N C E S

Vol. 42

(2017)

No. 2

ISSN 0867-6356

DE GRUYTER

DOI: $10.1515 /$ fcds-2017-0005

e-ISSN 2300-3405

\title{
TRUSTWORTHY ONLINE SHOPPING WITH PRICE IMPACT
}

\author{
Jedrzej MUSIAL *, Mario C. LOPEZ-LOCES †
}

\begin{abstract}
Internet shopping is one of the main pillars of electronic commerce. According to the literature, the Internet Shopping Optimization Problem (ISOP) has been defined in order to optimize the global cost of online purchase, taking into account both the cost of products and shipping. In this study, it was decided to propose and analyze a very interesting, and really substantial, extension of the ISOP. Namely, trust factors were subjected to careful analysis from the customer point of view. The analysis is based on a specially prepared questionnaire, supplemented by the information from the literature and our own observations. Thus, it was possible to propose a definition of a new mathematical model of the problem, and to prove its affiliation to the class of strongly NP-hard problems. In addition, the heuristic algorithm is proposed, which can be used to solve the problem.
\end{abstract}

Keywords: Internet shopping, e-Commerce, Trust factor, Applications of combinatorial optimization

\section{Introduction}

The adoption of online shopping by the users has been increasing steadily over the years. According to the study conducted by comScore for UPS [11] it reached the astounding figure of $\$ 213$ billion in 2013. Another survey conducted by Cisco with respondents from US, UK, China, Brazil and Mexico [14] states that eight of ten consumers from the markets of the aforementioned countries shops online, with the demographics groups from 18 to 29 and 30 to 39 in the lead.

In the future, this tendency will continue thanks to the emergence of the new online markets, especially in Asian countries, such as India [29], Indonesia [31], Taiwan [34],

\footnotetext{
*Institute of Computing Science, Poznan University of Technology, Poznan, Poland

${ }^{\dagger}$ Tecnologico Nacional de Mexico, Instituto Tecnologico de Ciudad Madero, Madero Tamaulipas, Mexico
} 
Jordan [1], Iran [12], Malaysia [3], etc. that offer a very interesting growth potential due to their large populations and relatively low e-commerce penetration rate. The advantages of purchasing products online for the client include that for them, it is not necessary to physically commute to a shopping mall or retail store, and that there is a wider range of options from where a customer can buy a product, which leads to lower prices, also with the emergence of mobile payments that offer additional convenience and security as perceived by the customers [27]. Also recently, thanks to the improvements in the delivery service, it has become possible to order perishable items such as food and groceries, which could eventually lead into a better management of this kind of products. This change from the supermarket to more efficient warehouses with better technology to preserve the food will hopefully translate into a reduced waste of this kind of resources in the near future [36].

When it comes to the seller, the main economic benefits include that it can reduce significantly costs associated with leasing and hiring of personal to help them to run the business. Also, as the phenomenon of e-commerce is relatively new and usually deals are based on different countries than the place of client's residence, they enjoy more liberty of action compared to their physical counterpart. Those conveniences for both clients and sellers that arise from e-commerce have made the number of online stores increase steadily. As for the sellers it is more convenient to join an existing online market or deploy their own website where they can offer their products. However, as convenient as this may sound, this convenience for the vendor can become the inconvenience for the customer. As mentioned before, more competition means lower prices, but also means that the customer can become overwhelmed with a huge number of options that makes it very difficult for him to get the best possible deal. This problem was initially modelled as the Internet Shopping Optimization Problem by [7] which was inspired by the work of Wojciechowski and Musial [32]. Moreover, it is worth noticing the collaborative approach that a coalition of shoppers can implement as a strategy to buy at the lowest costs [23].

Other concerns for most users that arise from e-commerce include the laxity of the regulations, which makes it easier for some untrustworthy or malicious sellers to deploy their own online stores. They facilitate user's lack of security that they experience when they provide their personal data and financial information in order to complete a transaction and the inability to inspect the items or try them before making the purchase [19].

With so much at stake, clients usually prefer to sacrifice better deals that are offered by less reputable sellers, to buy a more expensive product, offered by a known and trusted store with a higher rate of repurchase and better prestige among other consumers [35] [18]. Considering this behavior observed among most customers of online stores, we decided to extend the Internet Shopping Optimization Problem to include a rating for each e-commerce to additionally obtain the best possible price for a given shopping list, give the customer a set of options based on the reputability of the stores from a lower to higher risk.

The paper is organized as follows. Section 2 entails a literature review. The following Section 3 presents a survey with a detailed analysis and discussion on the answers and the results. Section 4 defines a new problem with its mathematical model 
definition, while Section 5 proposes an algorithmic approach to solve the problem. Conclusions (Section 7) summarizes the paper.

\section{Literature Review}

Price comparison sites had existed before the Internet Shopping Optimization Problem was defined. However, those kinds of online tools focus only on one item at a time, making it difficult to optimize the total price of a given shopping list by not taking advantage of discounts offered by stores on bulk purchases and delivery options [21]. Another concern that arises is that some of the price comparison sites are sponsored by private companies that have agreements to prioritize their own online shops or those of their partners.

The Internet Shopping Optimization Problem where a client wants to purchase a shopping list with a set of online stores that offer them with a minimum final price was initially proposed in [7]. Formally it was defined as follows:

A single buyer is looking for a multiset of products $N=\{1, \ldots, n\}$ to buy in $m$ shops. A multiset of available products $N_{l}$, a cost $c_{j l}$ of each product $j \in N_{l}$, and a delivery cost $d_{l}$ of any subset of the products from the shop to the buyer are associated with each shop $l, l=1, \ldots, m$. It is assumed that $c_{j l}=\infty$ if $j \notin N_{l}$. The problem is to find a sequence of disjoint selections (or carts) of products $X=\left(X_{1}, \ldots, X_{m}\right)$, which we call a cart sequence, such that $X_{l} \subseteq N_{l}, l=1, \ldots, m, \cup_{l=1}^{m} X_{l}=N$, and the total product and delivery cost, denoted as $F(X):=\sum_{l=1}^{m}\left(\delta\left(\left|X_{l}\right|\right) d_{l}+\sum_{j \in X_{l}} c_{j l}\right)$, is minimized.

In the paper it was proven that the problem belonged to the NP-Hard set by constructing a polynomial transformation from the Exact Cover by 3-Sets Problem (X3C) [15], where they also proposed polynomial time heuristics for the problem, one that focuses on enumerating all the possible selections of the shops that contain all the products in the shopping list, choosing the best selection [33] and the second enumerates for each product all the stores where it is available and selects the best shop sequence that minimizes the total cost [8].

The Internet Shopping Optimization Problem has been extended from its initial conception to include some of the most common features or situations that are present in real case scenarios. These variants of the problem include price sensitive discounts $[5,4,25]$ and dual discount functions [6] that offer discounts over the total price of a given shopping list and the latter adds a discount over the total delivery cost based on the total cost of the products, a practice that is common among retail and online stores. Further evaluation of the ISOP with its optimization can be found in [20] and $[24]$.

Another feature states, according to a survey conducted by the Nielsen Company [10] made with more than 27,000 online consumers from 55 markets around the world, that users of e-commerce platforms value the opinions and reviews of previous customers as a decisive factor in a possible acquisition of a product from a store. Zhang, 


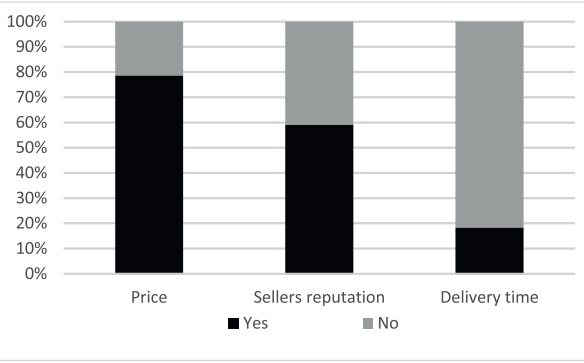

Figure 1. Key aspects when shopping online and their importance to the population.

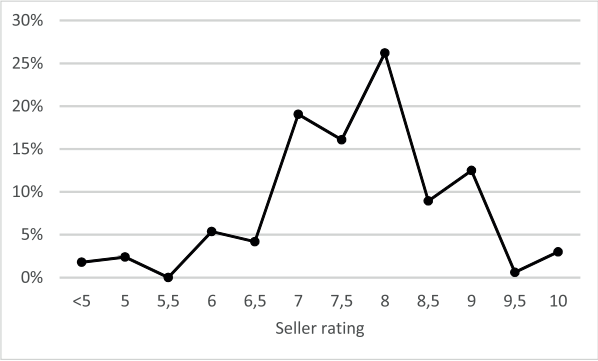

Figure 2. Minimum seller rating (1-10) required to interest the customer ( $\mathrm{Y}$ axis - percentage of population).

Cheung and Lee [37] examined interesting problem (question) of how inconsistent reviews play a role in consumers' online shopping decision.

Flanagin et al. [13] addressed the use of ratings problem to evaluate various online sellers and how the clients use them to select those online stores with better reputation to acquire their products. The use of those metrics can help to develop a system where a potential buyer can buy a list of products from reputable online businesses at the best cost.

\section{A Survey}

When preparing ISOP model with trust analysis we decided to support it by the literature [9] and our own observations. Therefore, a survey was prepared to complement with already mentioned information. The survey was carefully prepared. The goal was to receive answers to the most important questions regarding trust that a customer can bestow in sellers when shopping online in the Internet stores. We managed to gather 168 filled surveys. Afterwards, they were thoroughly analyzed [30]. The answers indicated in the survey allow to observe the following findings:

Almost $80 \%$ of respondents stated that the price is the key factor when choosing a store during their Internet shopping. This result is quite obvious and leaves no discussion. It is general knowledge that no matter what kind of products are tackled, price is an important factor. Especially when we look at the Internet shopping market where many offers from different stores are accessible from our own computer and sometimes visible at the same time. Just for a slightly less than $20 \%$ of participants, delivery time is an important factor. On the one hand, this observation could be surprising. However, very often we state quality, ratings and price over one additional day or two spent for delivery. Therefore, 137 people answer that delivery time is not an important factor. For $60 \%$ seller reputation will be very important / key factor. Figure 1 presents the percentage of yes/no when questioned about key factors when shopping online. 


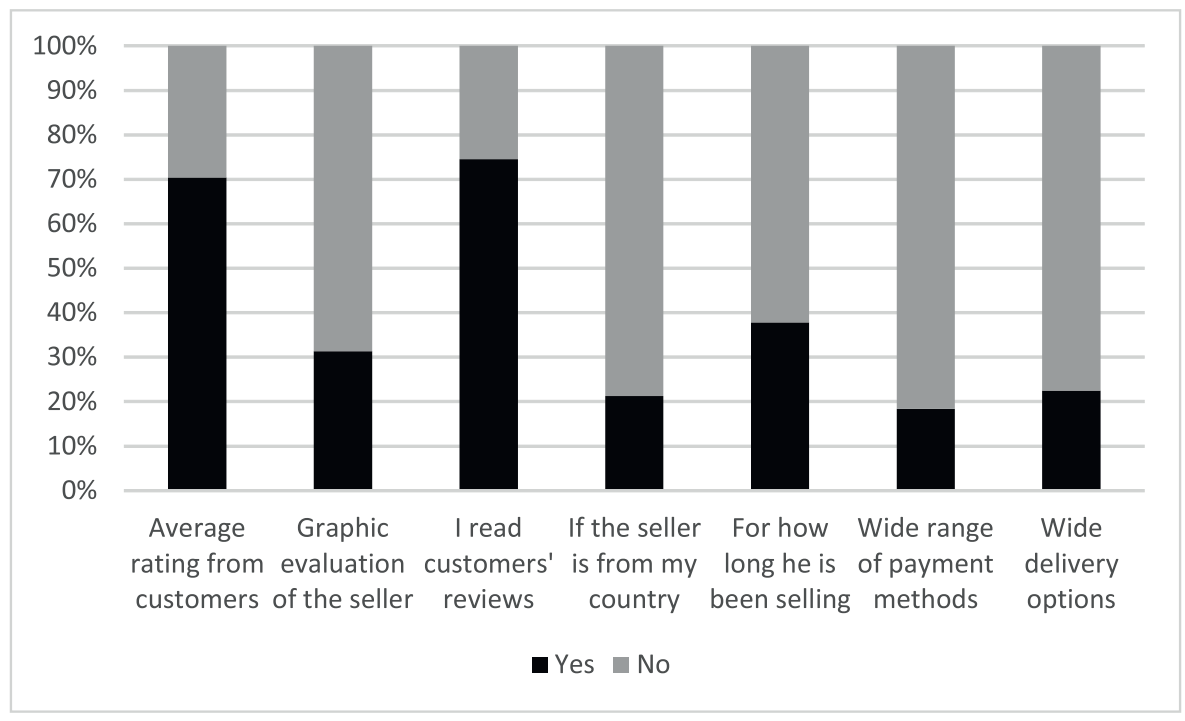

Figure 3. Different important aspects when a customer gathers information about seller.

Is numerical-based shop rating important? Do customers pay attention to it? $71 \%$ said "yes". This results can be connected with the next question on sellers general opinion / renown (gave by other customers). Is it important, and how important? Exactly for 159 persons (which reflects a vast group of 95\%) the opinions on shop are either very important, or significant. Just one person is not pay an attention to it. All in all, these two questions showed that when shopping from online stores we totally rely on other people that we often do not know. We find this as one of the most important conclusion from this survey.

Very often shops are marked by some graphical rating (e.g. stars). Only for $32 \%$ of respondents this factor is important. How it could be explained? Graphical ratings are much less accurate than numbers. Moreover, there is no strict rule how the sellers receives another mark, and under what requirements. In general if something is blur then it is less interesting for us. However, $32 \%$ is not a low percentage and that is why graphical ratings could be a very good supplement of the most crucial numericalbased rating and opinions (one should remember that the importance of this factor was marked by all the people). As a complementary results one can notice that $75 \%$ of respondents read the opinions written by other customers. This means that we prefer to spend some extra time (checking ratings is just the second compared to reading opinions) to get more detailed information about shops / sellers. What one would expect, but maybe not so obviously, is that people are not devoted to the local (their domestic country) shops. Only for $21 \%$ local (national) shops are more interesting. This could be connected either to some kind of a local support approach, either to some kind of fear / apprehension - delivery from other country, additional taxes, warranty aspects, etc. What was a little bit surprising is the fact that $38 \%$ 
of people who filled the survey stated that the length of the service of a shop is an important information regarding a seller. We did not expect that so many people would appreciate this fact. Nonetheless, it is obvious that the shops work experience increases its value / reputation (of course if the reputation is supported by positive opinions). It also appears that both wide variety of shipping and payment methods are not so significant. Only for $23 \%$ and $18 \%$ respectively of people it makes a difference. Please follow Figure 3 for the combined representation of the important aspects.

Our impression from the real life observations, as well as some known facts from the literature and general opinions is that people do not support sellers who are charging high for the delivery (who propose noticeable higher rates for the delivery than rest of the market). Surveys answers support this thesis. More than $2 / 3$ (69\%) of respondents state that they resign from shopping if delivery prices are too high, even if the prices of the products are appealing. We find this as a very important result and observation. How it could be explained? If one has to pay significantly more for the delivery than its market price he/she feels cheated. Immediately, a customer loses the interest and even the low prices of products do not encourage him to shop.

What should be the minimum sellers rating not to lose customers attraction? Rating below 5, in the 1-10 scale (measuring precision at 0.5 ) is suitable just for 3 persons $(1,8 \%)$. Rating of 5 is enough only for a very small group $(2.4 \%)$. The second step is rating equal to 6 . Shops with at least 6 already facilitate interest of $5.4 \%$ of respondents (we are not counting here a previously mentioned person). Another $4.2 \%$ stated than the rating should be at least 6.5 . Let us stop for the moment here and make a sub-summary. Shop that gather almost $2 / 3$ of the maximum grade (we can see that for e.g. hotel booking systems it is already not a bad mark) are interesting just for $13.8 \%$ of customers. Continuing the analysis one can see that $19.0 \%$ of respondents need not less than a numerical rating of 7 . Moreover, $16.1 \%$ declare that the sellers rating should be at least 7.5. The biggest group of respondents (exactly $26.1 \%$ ) wished to see rating 8 or more. For about $8.9 \%$ shops with at least 8.5 score will be trustworthy. A very high rating of at least 9 is obligatory for $12.5 \%$ of respondents. Rating of 9.5 and 10 is necessary for $0.6 \%$ and $3.0 \%$ respectively. The result dispersion is very, let us say, clean and stable. One should notice that 3 biggest groups support three neighboring rating values $(7,7.5,8)$, which covers more than $61 \%$ of the people. Two additional remarks are worth mentioning. Shops with almost $2 / 3$ of the maximum grade are interesting for just $13.8 \%$ of customers. And secondly, more than $16 \%$ accepts just top ranked stores (with a mark 9 or more). In general it shows that people have very high requirements in case of reputation / rank. Figure 2 illustrates present results, which are of the normal distribution shape.

Almost $73 \%$ of people will discredit sellers with a number of strongly negative opinions, even if they constitute a substantial minority. This shows that one bad opinion has much stronger weighted value (negative) than a positive one.

Very interesting aspect was a key question regarding the relation of price to rating calculation. $82.8 \%$ of respondents are eager to pay more for the products bought from the sellers with a good reputation. The biggest group (of more than $36.3 \%$ ) can pay additionally $10 \%$. A little bit smaller group of $31.0 \%$ declare to overpay $5 \%$ for this comfort. $12.5 \%$ can pay $20 \%$ more, $2.4 \%$ declared to spent even $30 \%$ more to have 
conveniences of renown seller. One respondent $(0.6 \%)$ can overpay the standard price by an unbelievable $40 \%$. However, one should notice that $17.2 \%$ don't want to pay any additional sum.

$36 \%$ of respondents will resign from shopping if the seller does not support their favorite shipping method. However, at the current Internet shopping market many stores and competitors offer similar, wide choice of shipping methods.

Last question was about customers own opinion (based on previous shopping or just on the feeling about a store). Answers distribution is almost the same as at the question regarding general store opinion - A huge group of $90 \%$ declared that their own opinion is either very important, or significant. Just for $7 \%$ it is not important at all (for the last $3 \%$ is less important).

Price is still one of the most important factors, however, we are sure that trust, reputation and the voice of customers are the most crucial. Clients are eager to pay significantly more (10-30\%) for the products from the well-rated sellers with flawless (or almost flawless) reputation.

\section{Demographical Data}

Below one can find demographical data of the respondents.

- Sex: 99 males, 69 females.

- Education: 73 secondary, 95 higher.

- Age range: number of representatives; <18: 2; 18-25: 92; 26-35: 58; 36-45: 13; 56-65: 2 ; >65: 1 .

- Inhabitancy: number of representatives; village: 18; small town: 10; 10-100 thousand city: 29; 100-500 thousand city: 36; 500-1000 thousand city: 50; > 1 million city: 26 .

\section{Problem Formulation}

Internet Shopping Optimization Problem arises when a customer wants to buy a number of products from Internet stores. Each desired product is offered by specific stores. Moreover, the shipping cost should be paid individually for each seller (flat rate for the most basic version of the problem). The original nature of the problem makes it very interesting and significant for current e-commerce. However, it was mentioned at the beginning of the paper that trust and confidence are very important when shopping online and this factor was completely omitted in the original ISOP discussions. We decided to build a new, more sophisticated model, which reflects real shopping situations more accurately. Trusted Internet Shopping Optimization Problem (T-ISOP) is presented in the following way: 


$$
\begin{array}{ll}
\min & \sum_{i=1}^{m} \sum_{j=1}^{n} x_{i j} \frac{p_{i j}}{\mathrm{OPay}_{j}} v_{j}+\sum_{j=1}^{n} y_{j} d_{j} \\
\text { s.t. } & \\
& \sum_{j=1}^{n} x_{i j}=1 \quad \forall i \in M \\
& \sum_{i=1}^{m} \sum_{j=1}^{n} x_{i j}=m \\
& m * y_{j}-\sum_{i=1}^{m} x_{i j} \geq 0 \quad \forall j \in N \\
& x_{i j} \in\{0,1\} \quad \forall i \in M, \forall j \in N \\
& y_{j} \in\{0,1\} \quad \forall j \in N \\
& O P a y_{j}=(1, \ldots, \max O p) \quad \forall j \in N \\
& v_{j} \in\{1, \infty\} \quad \forall j \in N
\end{array}
$$

where all the variables and symbols are described in Table 1.

Table 1. Table of notation

\begin{tabular}{cl}
\hline Symbol & Explanation \\
\hline$m$ & number of products to buy \\
$n$ & number of shops \\
$i$ & product indicator \\
$j$ & shop indicator \\
$d_{j}$ & delivery price for all products from shop $j$ \\
$y_{j}$ & usage indicator for delivery price from shop $j$ \\
$p_{i j}$ & cost of product $i$ in shop $j$ \\
$x_{i j}$ & usage indicator for product $i$ in shop $j$ \\
$O P a y_{j}$ & overpay trust function for shop $j$ \\
$v_{j}$ & trust veto factor for shop $j$ \\
\hline
\end{tabular}

After analysis of the literature (Section 2), the survey (Section 3) and gathering own experience the above general model could be presented in the following way (especially when we tackled two new functions, overpay (OPay) and veto $(v)$ ). One should notice that the above equations optimize the process of shop selection. When it is done, a customer will be charged for basic prices where the trust factor does not count $-\sum_{i=1}^{m} \sum_{j=1}^{n} x_{i j} p_{i j}+\sum_{j=1}^{n} y_{j} d_{j}$. Both OPay function and $v$ factor can be constructed according to the specific requirements. Function (OPay) represents combined trust factors and their impact on the price. Function returns values between 1 and $\max O p$ and reflects the cumulative trust overpay value - how much customer 
can pay additionally $($ Opay $* 100 \%)$ to buy products from a store with a very good reputation / rank. In theory $\operatorname{maxOp} \rightarrow \infty$. However, this is obviously a very improbable situation. The Survey (Section 3) answers show that the $\operatorname{maxOp}$ value for all the population was $1.4(=40 \%$ more expensive - and that value was acceptable just for one person). OPay function should be presented in the more detailed way. One should notice that we already described (Section 3) many factors that are important to customers (their general trust). General trust factor has an influence on the customers' decisions and very often they prefer to pay some extra for the desired products when shopping from trusted stores. OPay function can be modeled as:

$$
\begin{aligned}
\text { OPay }_{j} & =\text { overprice }_{j}+\text { Others }_{j} \quad \forall j \in N \\
\text { Others }_{j} & =d \text { dime }_{i j} * i s L_{j} * \text { dur }_{j} * \text { payR }_{j} * d O p t_{j} \quad \forall i \in M, \forall j \in N
\end{aligned}
$$

where overprice factor is calculated for each store $j$ to present what is the overpay value dedicated to the shop. dTime is the delivery time, isL asnwers the question is the seller is local (same country), $d u r$ is the seller's seniority, pay $R$ describes paymenet options range and $d O p t$ is delivery options range. In the future this function (like both OPay and veto functions) will be personalized to the user. This personalization process can be realized as a decision-aided questioner tool. For the general user purpose one can use data gathered from the survey and literature to prepare some default instance of the model values. Seeing that the most important factors are ratings and prices the overprice factor will be prepared as follows. One should create a matrix of rating / overpricing values pairs. All values pairs should be calculated according to the data. Moreover, average value and standard deviation will be calculated. For the normal distribution, the values more than two standard deviations from the mean $(\mu-2 \sigma, \mu+2 \sigma)$ will be cutoff leaving for the analysis $95.45 \%$ of the population (pairs), that will be included to the model and use accordingly with their calculated normal distribution.

The veto factor returns just two values, a negative (no veto) one that equals 1 and a positive one (veto) equals $\infty$. When it is positive, the offer should not be considered since a customers have some serious reservations to this seller. One should remember that the $v$ factor could be personalized following a customer's requirements and could be modeled as:

$$
\begin{aligned}
v_{j}= & \operatorname{rat}_{j} * \mathrm{del}_{j} * \operatorname{neg}_{j} * d \mathrm{Form}_{j} \quad \forall j \in N \\
& \operatorname{rat}_{j}, \mathrm{del}_{j}, \text { neg }_{j}, d \mathrm{dForm}_{j} \in\{1, \infty\} \quad \forall j \in N
\end{aligned}
$$

where rat is the seller's general rating. del answers the question regarding delivery options range, neg is the influence of negative opinions and dFrom is the delivery forms range.

Problem 1. The basic ISOP problem [7] can be transformed to the T-ISOP.

Statement 1. The T-ISOP is NP-Hard in the strong sense.

Proof. Let us consider the situation for which both overpay trust function (OPay) and trust veto factor $(v)$ equals 1 for every single shop $j\left(\forall_{j=1}^{n} O P a y_{j}=1, \forall_{j=1}^{n} v_{j}=1\right)$. 
Therefore, there is possible 1 to 1 transformation from the basic ISOP problem. Furthermore, the T-ISOP is NP-hard in the strong sense and there is no polynomial $(c \cdot \ln n)$-approximation algorithm for an T-ISOP problem, unless $\mathcal{P}=\mathcal{N} \mathcal{P}$.

\section{Algorithms Solving the Problem}

The results of the conducted survey showed that in most cases users value more reputation, that is based on solid security features on payment methods, the consistency of the quality of the products as displayed on the online store with those received by the user, and efficient delivery options, as well as the total cost of the shopping list.

The previously described situation can be noticed where stores, with lower reputation overall, try to lure new customers by reducing costs in contrast with more reputed and trusted sites that can afford to maintain or raise the costs of the products that they offer. In this case, the stores which offer the same prices of products and delivery options, the shop with the lower reputation could be safely vetoed, as it does not affect the outcome for those who prefer a lower total price of purchase over the rating of the stores selected.

An initial approach that could be applied to solve this variant of the ISOP that takes into consideration the reviews given by other clients is the use of a Genetic Algorithm $(G A)$. This method is inspired by the natural process of evolution by the natural selection that was described by Charles Darwin in 1858. The current form of the $G A$ was formalized by John Holland in de decade of the 1970's [17] as shown in Algorithm 1.

The GA starts by generation a population of random solutions, then it enters a loop that ends when a termination condition is met, usually a maximum number of generations. Inside the loop, two individuals $p 1$ and $p 2$ from the population are selected by a selection method. The selected individuals or parents are combined with a crossover method to produce a new solution or offspring. The offspring is perturbed by a mutation method and its fitness is determined. If the fitness of the offspring is better than the fitness of the worst solution in the population, the of fspring replaces it. When the termination condition is met, the best solution from the population is returned and the $G A$ finishes its process. 


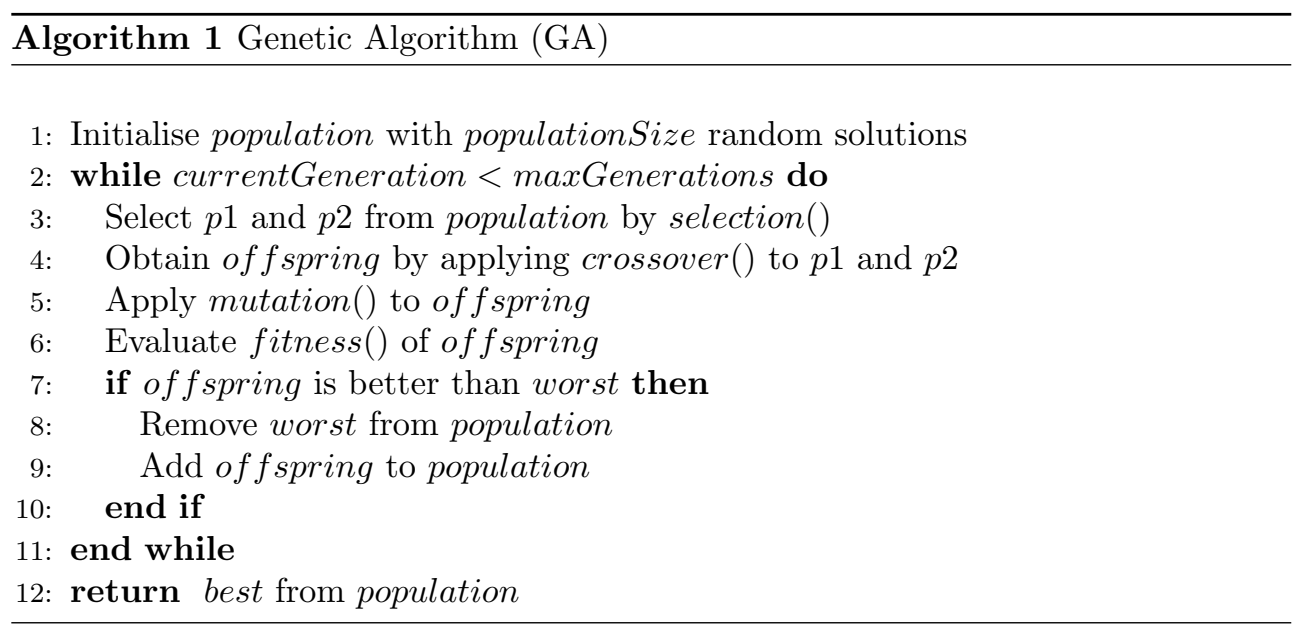

\section{Experimentation and Results}

The experimental data set consists of the two sets of 10 products and 20 stores $10 \mathrm{n} 20 \mathrm{~m}$ (10_20_1125, 10_20_1343, 10_20_1729, 10_20_2094, 10_20_3596, 10_20_4069, 10_20_4186, 10_20_4590, 10_20_5339, 10_20_5721) and 20 products and 20 stores 20n20m (20_20_1085, 20_20_1207, 20_20_1413, 20_20_1535, 20_20_1817, 20_20_2321, 20_20_2329, 20_20_3361, 20_20_3869, 20_20_4207) that can be found in the IShOP project website ${ }^{1}$.

The last number of each instance name was used as the seed to generate normally distributed random numeric ratings for each store, with an average value of 7 and a standard deviation of 2 .

Three veto values $(3,6,9)$ were used for the experimentation. Stores with a higher or equal value to the veto are considered in the purchase of the products on the shopping list. The veto value of 0 was used as a control where all stores were considered, independently of their rating.

The overpay function $\mathrm{T}$ was defined with the following values:

$$
T(x)= \begin{cases}\operatorname{prodCost}(x) * 1.0, & \text { if } 0 \leq \operatorname{rating}(x) \leq 1 \\ \operatorname{prodCost}(x) * 1.05, & \text { if } 1<\operatorname{rating}(x) \leq 4 \\ \operatorname{prodCost}(x) * 1.1, & \text { if } 4<\operatorname{rating}(x) \leq 7 \\ \operatorname{prodCost}(x) * 1.2, & \text { if } 7<\operatorname{rating}(x) \leq 9 \\ \operatorname{prodCost}(x) * 1.3, & \text { if } 9<\operatorname{rating}(x) \leq 10\end{cases}
$$

where $x$ represents a store, $\operatorname{prodCost}(x)$ the products of the shopping list that were purchased in the store $x$, and rating $(x)$ the rating that the store $x$ has according to other customers.

\footnotetext{
${ }^{1}$ http://www.cs.put.poznan.pl/ishop/
} 
The population of the $G A$ was set to 50 individuals, with a maximum number of 25,000 generations. The selection operator used was the Binary Tournament Selection. The crossover operator used was the Integer Simulated Binary Crossover, with a crossover probability of 0.9 , and the mutation operator used was the Integer Polynomial Mutation, with a mutation probability of 0.05 . There was no time limit for solving the instances in the computational experiment.

Table 2 shows the results of the computational experiment, the first column shows the different veto values considered. For each veto value and instance set, the accumulated time in milliseconds that took the $G A$ to solve all the instances in an instance set, the average rating of the stores selected for the final solutions and the average objective value or total cost of the shopping list of the instances of each set were calculated.

Table 2. Results of the computational experiment

\begin{tabular}{llrr}
\hline & & 10n20m & 20n20m \\
\hline \multirow{3}{*}{ veto $=9$} & Time $(m s)$ & 2279 & 2613 \\
& AvgRating & 9.49 & 9.42 \\
& OV & 133.73 & 330.49 \\
\cline { 2 - 4 } veto $=6$ & Time $(\mathrm{ms})$ & 2085 & 2493 \\
& AvgRating & 7.65 & 7.71 \\
veto $=3$ & OV & 100.51 & 155.18 \\
\cline { 2 - 4 } & Time $(\mathrm{ms})$ & 2049 & 2567 \\
& AvgRating & 5.84 & 6.72 \\
veto $=0$ & 83.43 & 157.89 \\
\cline { 2 - 4 } & Oime $(\mathrm{ms})$ & 2209 & 2594 \\
& AvgRating & 6.35 & 6.76 \\
& OV & 87.59 & 172.58 \\
\hline
\end{tabular}

It can be observed that the total cost of the shopping list increases with the average rating of the stores selected, which indicates that the T-ISOP could be modelled in the future as a bi-objective optimization problem. The experiment should be perceived as an important initial step that opens wide possibilities for future research, where the real data collected from the stores can be used to enhance the algorithm design, optimization and use a more detailed T-ISOP model.

The counterintuitive results among the solutions obtained with veto 0 and 3 can be explained by the method to generate the ratings, that makes lower values extremely rare, and the small difference between the overpay percentage on stores with a rating of less than four. 


\section{Conclusion}

In this study, we analyzed an extension of the ISOP and formulated Trusted Internet Shopping Optimization Problem (T-ISOP). Namely, trust factors were subjected to a careful analysis from the customer point of view. The analysis is based on a specially prepared questionnaire, supplemented by the information from the literature and our own observations. Thus, it was possible to propose a definition of a new mathematical model of the problem, and to prove its affiliation to the class of strongly NP-hard problems. Many interesting observations and discussion were presented in the paper.

In addition, the algorithm is proposed, which can be used to solve the problem efficiently. Future work will involve deep analysis of trust factor and combine it with the optimization of the problem (also from more technical point of view [22]). Furthermore, it will be inspiring to enrich cloud brokering problem [16] with the trust factor analysis. Cloud brokering is a vibrant topic and according to our best knowledge it lacks and suffer from adequate (or even whatsoever) trust and reputation factors influence on the market.

From the other point of view, an interesting future research idea is to prepare computational experiments on the basis of real data. Simple decision-aid simulation tool could be another interesting research point. Moreover, it could be beneficial to use biology inspired approaches, models [26] and computations [28, 2] to tackle the problem. Furthermore, both OPay and $v$ functions could be personalized to the user. This personalization process will be realized as a decision-aided questioner tool. This allows to prepare experimental analysis dedicated to each single user accordingly to his detailed needs and requirements. All these steps, however, require a huge amount of upcoming, exciting work.

\section{References}

[1] Abdullah al-Qudah O., Ahmad K., The roles of culture in online shopping to enhance e-commerce in Jordan, in: Proceedings of the 6th International Conference on Information Technology and Multimedia, IEEE, 2014, 113-117.

[2] Antczak M., Kasprzak M., Lukasiak P., Blazewicz J., Structural alignment of protein descriptors - a combinatorial model, BMC Bioinformatics, 17, 1, 2016, 383.

[3] Ariff M.S.M., Sylvester M., Zakuan N., Ismail K., Ali K.M., Consumer Perceived Risk, Attitude and Online Shopping Behaviour; Empirical Evidence from Malaysia, in: IOP Conference Series: Materials Science and Engineering, 58, IOP Publishing, 2014.

[4] Blazewicz J., Bouvry P., Kovalyov M.Y., Musial J., Erratum to: Internet shopping with price-sensitive discounts, $4 O R-A$ Quarterly Journal of Operations Research, 12, 4, 2014, 403-406. 
[5] Blazewicz J., Bouvry P., Kovalyov M.Y., Musial J., Internet shopping with price sensitive discounts, 4OR-A Quarterly Journal of Operations Research, 12, 1, 2014, 35-48.

[6] Blazewicz J., Cheriere N., Dutot P.F., Musial J., Trystram D., Novel dual discounting functions for the Internet shopping optimization problem: new algorithms, Journal of Scheduling, 19, 3, 2016, 245-255.

[7] Blazewicz J., Kovalyov M., Musial J., Urbanski A., Wojciechowski A., Internet shopping optimization problem, International Journal of Applied Mathematics and Computer Science, 20, 2, 2010, 385-390.

[8] Blazewicz J., Musial J., E-Commerce Evaluation - Multi-Item Internet Shopping. Optimization and Heuristic Algorithms, in: B. Hu, K. Morasch, S. Pickl, M. Siegle (eds.), Operations Research Proceedings 2010: Selected Papers of the Annual International Conference of the German Operations Research Society, Springer Berlin Heidelberg, 2011, 149-154.

[9] Chu W., Choi B., Song M., The Role of On-line Retailer Brand and Infomediary Reputation in Increasing Consumer Purchase Intention, International Journal of Electronic Commerce, 9, 2005, 115-127.

[10] Nielsen Company, Global Online Shopping Report, 2014, http://www . nielsen. com/us/en/insights/news/2010/global-online-shopping-report.html.

[11] comScore, UPS Pulse of the Online Shopper, A customer experience study, 2014, http://www . ups.com/media/en/2014-UPS-Pulse-of-the-Online-Shopper. pdf.

[12] Dehnavi M.H., Shirazi A., Zhourian M., The Influence of Cultural variables on Online Shopping (A survey of cultural effects on online users' behavior in Iran), Asian Journal of Research in Marketing, 3, 2, 2014, 168-183.

[13] Flanagin A.J., Metzger M.J., Pure R., Markov A., Hartsell E., Mitigating risk in ecommerce transactions: perceptions of information credibility and the role of user-generated ratings in product quality and purchase intention, Electronic Commerce Research, 14, 1, 2014, 1-23.

[14] Fretwell L., Stine J., Sethi H., Noronha A., 'Catch and Keep' Digital Shoppers How To Deliver Retail Their Way, 2013, http://www.cisco.com/web/about/ ac79/docs/retail/Catch-and-Keep-the-Digital-Shopper_PoV.pdf.

[15] Garey M., Johnson D., Computers and intractability: a guide to the theory of NP-completeness, WH Freeman \& Co., San Francisco, 1979.

[16] Guzek M., Gniewek A., Bouvry P., Musial J., Blazewicz J., Cloud Brokering: Current Practices and Upcoming Challenges, IEEE Cloud Computing, 2, 2, 2015, 40-47. 
[17] Holland J., Adaptation in artificial and natural systems, Ann Arbor: The University of Michigan Press, 1975.

[18] Hsu M.H., Chuang L.W., Hsu C.S., Understanding online shopping intention: the roles of four types of trust and their antecedents, Internet Research, 24, 3, 2014, 332-352.

[19] Kumar S., Maan S., Status and Scope of Online Shopping: An Interactive Analysis through Literature Review, International Journal of Advance Research in Computer Science and Management Studies, 2, 12, 2014, 100-108.

[20] Lopez-Loces M.C., Musial J., Pecero J.E., Fraire-Huacuja H.J., Blazewicz J., Bouvry P., Exact and heuristic approaches to solve the Internet shopping optimization problem with delivery costs, International Journal of Applied Mathematics and Computer Science, 26, 2, 2016, 391-406.

[21] Maes P., Guttman R.H., Moukas A.G., Agents that buy and sell, Communications of the ACM, 42, 3, 1999, 81-ff.

[22] Marszalkowski J., Marszalkowski J.M., Musial J., Database Scheme Optimization For Online Applications, Foundations of Computing and Decision Sciences, 36, 2, 2011, 121-129.

[23] Monica D.D., Napoli M., Parente M., On a Logic for Coalitional Games with Priced-Resource Agents, Electronic Notes in Theoretical Computer Science, 278, $2011,215-228$.

[24] Musial J., Pecero J.E., Lopez-Loces M.C., Fraire-Huacuja H.J., Bouvry P., Blazewicz J., Algorithms solving the Internet shopping optimization problem with price discounts, Bulletin of the Polish Academy of Sciences Technical Sciences, 64, 3, 2016, 505-516.

[25] Orciuoli F., Parente M., Vitiello A., Solving the shopping plan problem through bio-inspired approaches, Soft Computing, 20, 5, 2016, 2077-2089.

[26] Prejzendanc T., Wasik S., Blazewicz J., Computer Representations of Bioinformatics Models, Current Bioinformatics, 11, 5, 2016, 551-560.

[27] Shin S., Lee W.J., Odom D.O., A Comparative Study Of Smartphone User's Perception And Preference Towards Mobile Payment Methods In The US And Korea, Journal of Applied Business Research (JABR), 30, 5, 2014, 1365-1375.

[28] Szostak N., Wasik S., Blazewicz J., Hypercycle, PLOS Computational Biology, 12, 4, 2016, 1-13.

[29] Thakur R., Srivastava M., Towers N., A study on the impact of consumer risk perception and innovativeness on online shopping in India, International Journal of Retail $\&$ Distribution Management, 43, 2, 2015. 
[30] The University of Reading Statistical Services Centre - Biometrics Advisory and Support Service to DFID, Approaches to the Analysis of Survey Data, 2001, http://archive.acehresearch.org/items/show/69.

[31] Warayuanti W., Suyanto A., The Influence of Lifestyles and Consumers Attitudes on Product Purchasing Decision via Online Shopping in Indonesia, European Journal of Business and Management, 7, 8, 2015, 74-80.

[32] Wojciechowski A., Musial J., A customer assistance system: Optimizing basket cost, Foundations of Computing and Decision Sciences, 34, 1, 2009, 59-69.

[33] Wojciechowski A., Musial J., Towards Optimal Multi-item Shopping Basket Management: Heuristic Approach, in: R. Meersman, T. Dillon, P. Herrero (eds.), On the Move to Meaningful Internet Systems: OTM 2010 Workshops, Lecture Notes in Computer Science, 6428, Springer Berlin Heidelberg, 2010, 349-357.

[34] Wong M., Evaluating Online Shopping Service Quality-SERVEGAL in Taiwan Tourism Industry, Open Journal of Social Sciences, 2, 09, 2014, 213.

[35] Wu L.Y., Chen K.Y., Chen P.Y., Cheng S.L., Perceived value, transaction cost, and repurchase-intention in online shopping: A relational exchange perspective, Journal of Business Research, 67, 1, 2014, 2768-2776.

[36] Xiang X., Jiashi L., Zhongliang G., Xinsheng K., Fresh Food Online Supermarket Development Study, Journal of Electronic Commerce in Organizations (JECO), 12, 2, 2014, 14-30.

[37] Zhang K.Z., Cheung C.M., Lee M.K., Examining the moderating effect of inconsistent reviews and its gender differences on consumers' online shopping decision, International Journal of Information Management, 34, 2, 2014, 89-98.

Received 3.02.2017, Accepted 20.04.2017 